\title{
Repeated 5-aminolevulinic Acid Instillations During Follow-up in Non-muscle-invasive Bladder Cancer: A Randomized Study
}

\author{
EIJA KELLONIEMI ${ }^{1}$, RIIKKA JÄRVINEN ${ }^{1}$, PEKKA HELLSTRÖM ${ }^{2}$, ERKKI RINTALA ${ }^{1}$, \\ SIRPA AALTOMAA ${ }^{3}$, TAINA ISOTALO ${ }^{4}$, KALMER INNOS $^{4}$ and EERO KAASINEN ${ }^{5}$ \\ ${ }^{1}$ Department of Urology, Helsinki University Hospital, Helsinki, Finland; \\ ${ }^{2}$ Department of Urology, Oulu University Hospital, Oulu, Finland; \\ ${ }^{3}$ Department of Urology, Kuopio University Hospital, Kuopio, Finland; \\ ${ }^{4}$ Department of Surgery, Päijät-Häme Central Hospital, Lahti, Finland; \\ ${ }^{5}$ Department of Surgery, Hyvinkää Hospital, Hyvinkää and Helsinki University Hospital, Hyvinkää, Finland
}

\begin{abstract}
Background/Aim: Non-muscle invasive bladder carcinoma (NMIBC) is highly recurrent. We studied if 5aminolevulinic acid (5-ALA) instillations before transurethral resection of bladder tumours (TURBT) and cystoscopy extend the time to recurrence during follow-up with NMIBC patients. Patients and Methods: A prospective multicenter study enrolled 328 NMIBC patients. All TURBTs and control cystoscopies during the one-year study period were done with or without 5-ALA instillations. The primary endpoint was time to recurrence. The secondary endpoints were time to recurrence after $7.5,10.5$, and 13.5 months and the number of patients with progressive disease. Results: The overall median follow-up time was 80.4 and 87.0 months for the control and study groups, respectively. There was no statistical difference in time to first recurrence between the two groups. Conclusion: We could not obtain significant differences between the control and 5-ALA groups in tumour recurrence among patients with $N M I B C$.
\end{abstract}

At the time of detection, approximately $75 \%$ of bladder tumours were non-muscle invasive (NMI), presenting with the following tumour stages: Ta, carcinoma in situ (CIS), and T1 (1). According to UICC 2009 classification Ta stage is defined as "papillary tumour confined to the mucosa", T1 as

This article is freely accessible online.

Correspondence to: Eija Kelloniemi, HUCH Abdominal Center/ Department of Urology, HUCH Helsinki University Hospital, Sairaalakatu 1, 00290, Helsinki, Finland. Tel: +35894711, e-mail: eija.kelloniemi@hus.fi

Key Words: Non-muscle-invasive bladder cancer, 5-aminolevulinic acid, fluorescence cystoscopy, photodynamic diagnosis, tumour detection. "papillary tumour invading the lamina propria" and Carcinoma in situ as "flat high grade tumour which is confined to the mucosa" (2). During surveillance, recurrences are found in $50-70 \%$ of patients and $10-20 \%$ will subsequently progress to muscle-invasive disease (3-5). At presentation, approximately $70 \%$ of NMIBC patients have a Ta stage tumour, $20 \%$ a T1 stage, and $5-10 \%$ carcinoma in situ (CIS) (6-7). Early stage NMI bladder carcinoma (NMIBC) tumours are difficult to diagnose because of their multifocal nature or because they appear as flat lesions with no thickening of the epithelium, such as CIS and dysplasia, which are often covered by non-specific inflammatory changes of the urothelial membrane (8). The quality and completeness of transurethral resection of bladder tumours (TURBT) depends on the experience of the urologist and the visibility of the tumours. Detection failure can lead to residual tumours and/or recurrence or even progression. After conventional white light TURBT, prevalence of residual tumours have been up to $43 \%$ indicating an incomplete resection in the first TURBT (9).

Conventional cystoscopy is suboptimal for the detection of flat or small bladder tumours. Photodynamic diagnosis (PDD), also referred to as fluorescence or blue light cystoscopy, is an adjunct to white light cystoscopy, and is used to improve the detection of bladder tumours. Kriegmair et al. first reported the intravesical administration of 5-ALA (Medac, Wedel, Germany) for use in fluorescence cystoscopy (10). In that study, no adverse events were noted (10). Hungerhuber et al. found that the advantage of PDD was most pronounced in the detection of CIS and dysplasia, as $43.4 \%$ of carcinoma in situ and $30.7 \%$ of grade 2 dysplasia were detected only by PDD (11). To date, a lot of data have accumulated on 5-ALA cystoscopy, including data on long-term follow-up (12-16). More recently, hexaminolevulinic acid (HAL, Hexvix ${ }^{\circledR}$, Photocure ASA, Oslo, Norway) was designed by esterification of the 


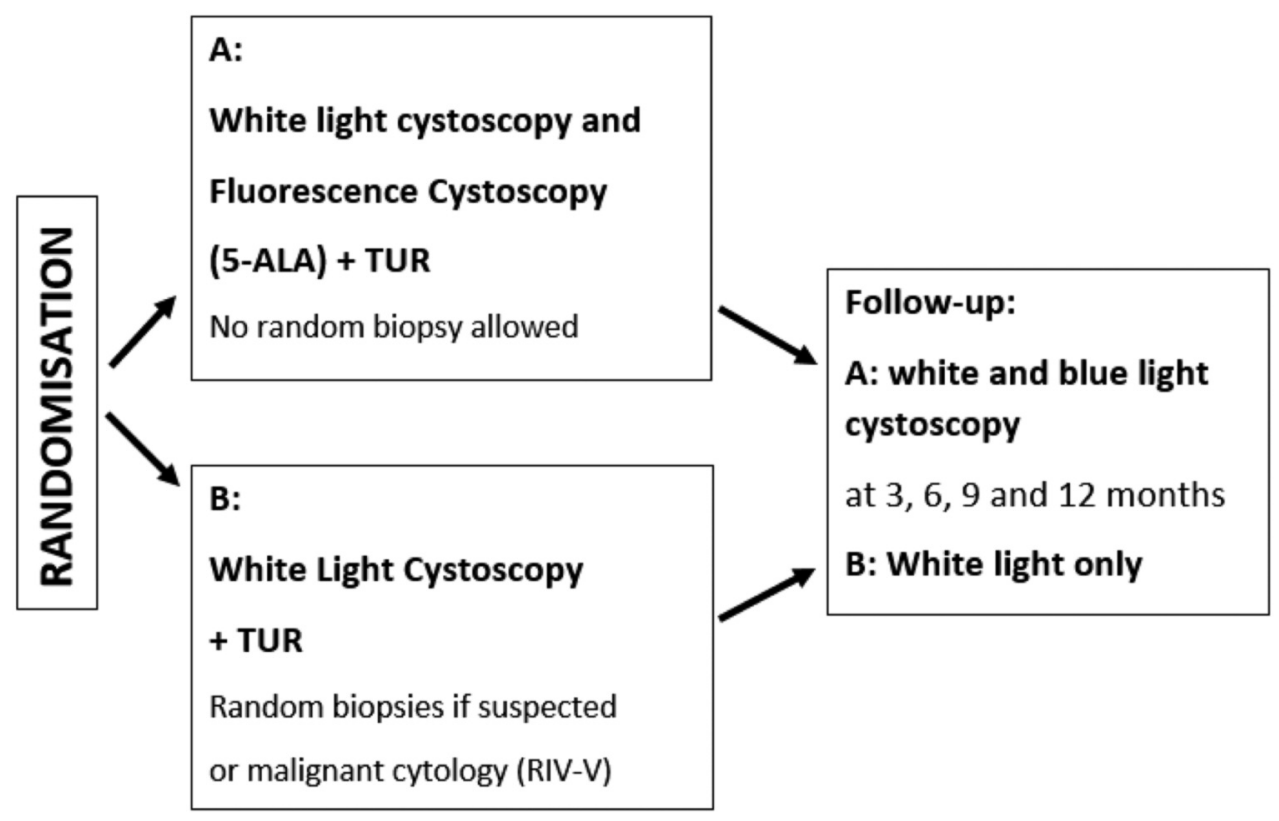

Figure 1. After randomization, treatments in the A group were done with a blue light and in the B group with a white light. During a one-year study period, control cystoscopies were realized every three months in both groups. WL: White light group; 5-ALA: 5-aminolevulinic acid group; TUR: transurethral resection of bladder tumour.

molecule. This 5-ALA derivative seemed more practical to use, having an instillation time of only $1 \mathrm{~h}$ preceding cystoscopy compared to that of 2-4 $\mathrm{h}$ for 5-ALA. 5-ALA is not officially approved for fluorescence cystoscopy, whereas HAL has been approved since May 2010 as a compound for use only in the diagnosis for bladder cancer in Europe and USA. The aim of the present study was to evaluate and compare the diagnostic efficacy between 5-ALA-induced blue light cystoscopy/TURBT and WL cystoscopy/TURBT in suspicious lesions with respect to tumour recurrence. More specifically, we were interested in the effect of repeated 5-ALA instillations during follow-up.

\section{Patients and Methods}

Inclusion criteria were suspected primary or recurrent NMIBC based on at least one documented imaging procedure such as cystoscopy, sonography, X-ray (urography, CT), positive cytology or positive BTA stat test (BTA stat ${ }^{\circledR}$, RB Incorporation, Ahmedabad, Gujarat, India). The patient was required be at least 20 years of age. Patients with grade 3 disease and those with T category higher than T1 were excluded from the study. Bladder instillations for prevention of recurrence were not allowed in the first year.

A total of 328 patients were enrolled in a prospective randomised multicenter study conducted by the FinnBladder Group between 8 October 2002 and 17 December 2007. After receipt of written informed consent signed by the patients, the FinnBladder randomization center was contacted by telephone or fax, after which each patient was registered and allocated to one of two treatment groups. In the 5-ALA group, cystoscopies and TURBTs were performed two hours after 5-ALA instillation. 5-ALA was used similarly preceding the TURBT and four cystoscopies during the first year of follow-up. The 5-ALA (Medac GmbH, Wedel, Germany) used in the study was a dry powder dissolved just before its instillation in the urinary bladder (1.5 g of 5-ALA dissolved in $50 \mathrm{ml}$ of solvent containing $1.4 \%$ of sodium bicarbonate). In the white light (WL) group, these operations were done conventionally without the preceding 5-ALA instillation (Figure 1).

The cystoscopes were from Olympus (Olympus Europa SE \& CO.KG, Hamburg, Germany) and Wolf (Richard Wolf $\mathrm{GmbH}$, Knittlingen, Germany).

The study was done in accordance with Good Clinical Practice and the Declaration of Helsinki and was approved by the local medical ethics committee, Helsinki University Hospital, Helsinki.

The study protocol stipulated that patients with CIS and dysplasia were to be included and followed for up to 3 months. However, during the final analysis, the CIS and dysplasia patients were finally removed from the study because of the small numbers and the fact that instillation therapy had been started in many of them. As many as 139 (42.4\%) patients were ineligible for the follow-up analysis. Randomization characteristics of the remaining 189 eligible patients are shown in Table I. The reasons for ineligibility are listed in Table II.

Patients were evaluated every 3 months during the first year, and thereafter according to local practice. The evaluation involved cytology, BTA stat tests, cystoscopy and biopsies of suspicious lesions.

The sample size calculation was based on the assumed 12-month tumour rates of $60 \%$ for the WL group and $40 \%$ for the 5-ALA group. Using the non-parametric logrank-based statistics in a twotailed test with an alpha value of 0.05 and a beta value of $0.10,131$ patients were calculated to be required in each group. However, after taking into account an expected $10 \%$ of patients dropping out 
Table I. Randomization characteristics of eligible patients.

\begin{tabular}{|c|c|c|c|c|c|c|c|}
\hline & WL & $\%$ & 5-ALA & $\%$ & All & $\%$ & $p$-Value \\
\hline Eligible for analysis & 97 & 51.3 & 92 & 48.7 & 189 & & $0.7^{\mathrm{a}}$ \\
\hline Gender & & & & & & & $0.9^{\mathrm{a}}$ \\
\hline Male & 68 & 70.1 & 65 & 70.7 & 133 & 70.4 & \\
\hline Female & 29 & 29.9 & 27 & 29.3 & 56 & 29.6 & \\
\hline \multicolumn{8}{|l|}{ Age (years) } \\
\hline Median & 69.3 & & 69.0 & & 69.2 & & $0.6^{\mathrm{b}}$ \\
\hline $1^{\text {st }}$ quartile & 62.0 & & 60.7 & & 61.4 & & \\
\hline $3^{\text {rd }}$ quartile & 77.2 & & 76.8 & & 77.0 & & \\
\hline Primary tumors & 70 & 72.2 & 72 & 78.3 & 142 & 75.1 & $0.3^{\mathrm{a}}$ \\
\hline Recurrent tumors & 27 & 27.2 & 20 & 21.7 & 47 & 24.9 & $0.3^{\mathrm{a}}$ \\
\hline \multicolumn{8}{|l|}{$\mathrm{T}$ category and grade } \\
\hline PUNLMP & 20 & 20.6 & 12 & 13.0 & 32 & 16.9 & $0.3^{\mathrm{a}}$ \\
\hline pTaG1 & 45 & 46.4 & 42 & 45.7 & 87 & 46.0 & $0.3^{\mathrm{a}}$ \\
\hline $\mathrm{pTaG} 2$ & 17 & 17.5 & 24 & 26.1 & 41 & 21.7 & \\
\hline pT1G1 & 5 & 5.2 & 2 & 2.2 & 7 & 3.7 & \\
\hline pT1G2 & 10 & 10.3 & 12 & 13.0 & 22 & 11.6 & \\
\hline \multicolumn{8}{|l|}{ Cytology } \\
\hline Negative & 54 & 55.7 & 52 & 56.5 & 106 & 56.1 & $0.9^{\mathrm{a}}$ \\
\hline Positive & 6 & 6.2 & 7 & 7.6 & 13 & 6.9 & $0.9^{\mathrm{a}}$ \\
\hline Inadequate & 20 & 20.6 & 15 & 16.3 & 35 & 18.5 & \\
\hline Not available & 17 & 17.5 & 18 & 19.6 & 35 & 18.5 & \\
\hline \multicolumn{8}{|l|}{ BTA stat } \\
\hline Negative & 33 & 34.0 & 26 & 28.3 & 59 & 31.2 & $0.2^{\mathrm{a}}$ \\
\hline Positive & 12 & 12.4 & 6 & 6.5 & 18 & 9.5 & $0.2 \mathrm{a}$ \\
\hline Not available & 52 & 53.6 & 60 & 65.2 & 112 & 59.3 & \\
\hline
\end{tabular}

WL: White light group; 5-ALA: 5-aminolevulinic acid group; PUNLMP: papillary urothelial neoplasia of low malignant potential; 1973 WHO grading: Grade 1: well differentiated, Grade 2: moderately differentiated, Grade 3: poorly differentiated. ${ }^{\mathrm{a} C h i}$ square statistics, ${ }^{\mathrm{b}}$ Mann-Whitney $U$-test.

Table II. Reasons for ineligibility.

\begin{tabular}{|c|c|c|c|c|c|c|}
\hline & WL & $\%$ & 5-ALA & $\%$ & All & $\%$ \\
\hline No carcinoma in the specimen & 27 & 39.7 & 25 & 35.2 & 52 & 37.4 \\
\hline Histological report missing & 14 & 20.6 & 11 & 15.5 & 25 & 18.0 \\
\hline $\mathrm{T} 2$ or more advanced disease & 10 & 14.7 & 9 & 12.7 & 19 & 13.7 \\
\hline CIS & 7 & 10.3 & 9 & 12.7 & 16 & 11.5 \\
\hline pT1 G3 & 5 & 7.4 & 6 & 8.5 & 11 & 7.9 \\
\hline pTa G3 & 3 & 4.4 & 1 & & 4 & 2.9 \\
\hline No follow-up & 1 & & 3 & 4.2 & 4 & 2.9 \\
\hline Ureteral carcinoma & 1 & & & & 1 & \\
\hline BCG started after randomisation & & & 3 & 4.2 & 3 & 2.2 \\
\hline 5-ALA not used & & & 3 & 4.2 & 3 & 2.2 \\
\hline Second cancer & & & 1 & & 1 & \\
\hline Total & 68 & & 71 & & 139 & \\
\hline
\end{tabular}

WL: White light group; 5-ALA: 5-aminolevulinic acid group; BCG: bacillus Calmette-Guérin.

as well as an expected $25 \%$ of patients without tumour at randomization or with poorly differentiated (G3) disease or T2 or higher, the required number of patients was increased to 180 patients for each group, resulting in a total number of 360 (17).

The objective of the study was to compare the diagnostic efficacy of 5-ALA-induced fluorescence cystoscopy/TURBT to that of white light cystoscopy/TURBT with respect to tumour recurrence. The primary endpoint was time to first recurrence. In the study protocol, the secondary endpoints were recurrence rate at 3,6, 9, and 12 months, number of progressions, number of lesions detected, and disease-free status of Cis and dysplastic lesions at 3 months. After preliminary analyses and exclusion of patients with CIS and 


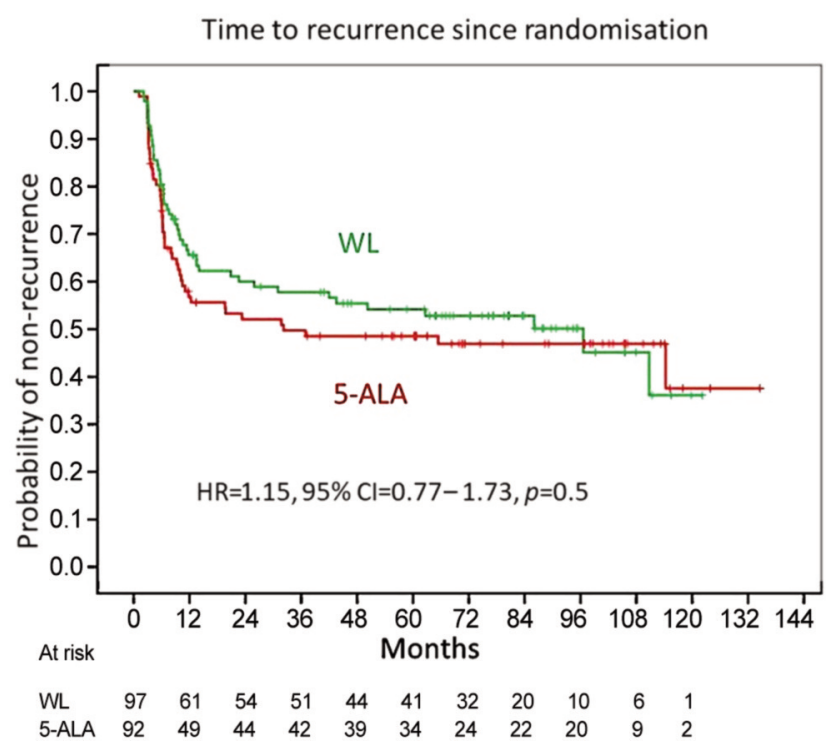

Figure 2. Kaplan-Meier curves showing time to first recurrence since randomization. WL: White light group; 5-ALA: 5-aminolevulinic acid group; HR: hazard ratio; CI: confidence interval.

dysplasia, the secondary endpoints were modified, and these were subsequently defined as time to recurrence after 7.5, 10.5 and 13.5 months, in addition to the number of patients with progressive disease. The aforementioned time points correspond to the scheduled cystoscopies at 6,9 , and 12 months, respectively, with possible delays in performing them being taken in to account. Recurrence was defined as a biopsy-confirmed NMIBC (TaT1) or CIS, or positive cytology. Progression was defined as T2 or more advanced disease. If progression was the first event without preceding recurrence, then it was also regarded as recurrence in the disease-free analysis. Recurrence after 7.5, 10.5, and 13.5 months was defined as the first recurrence after the time point or progression before the time point. Recurrences apart from progressions before the time point were not considered as events. For statistical analysis, we used SPSS (version 22.0.0.1, IBM, NY, USA) provided by the Helsinki University Hospital. The KaplanMeier method was the principal tool in demonstrating the time to recurrence, whereas the univariable Cox proportional hazards model was the method used to estimate the statistical significance between the two treatment groups. Chi-square statistics were used in the cross-tabulations. The Mann-Whitney $U$-test was used to compare the distributions around two medians. A $p$-Value less than 0.05 was considered to be statistically significant.

\section{Results}

The overall median follow-up time was 80.4 months (maximum 149.9 months) for the 97 patients in the WL group and 87.0 months (maximum 153.2 months) for the 92 patients in the 5-ALA group. Regarding the primary endpoint which was time to first recurrence, no statistical difference was found between the two treatment groups [hazard ratio
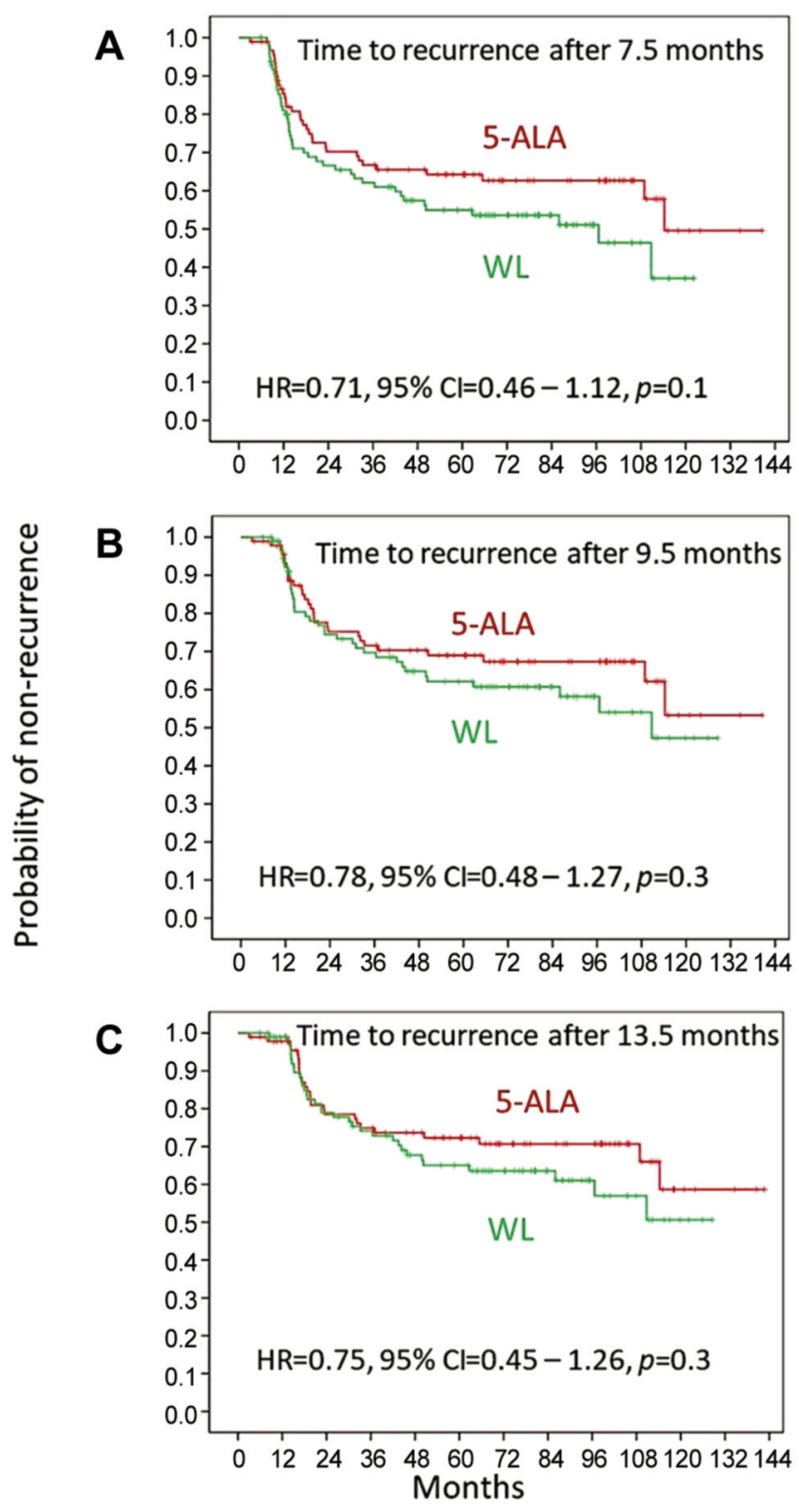

Figure 3. Kaplan-Meier curves showing time to recurrence after $7.5(A)$, 9.5 (B), and 13.5 months $(C)$. WL: White light group; 5-ALA: 5aminolevulinic acid group; HR: hazard ratio; CI: confidence interval.

$(\mathrm{HR})=1.15,95 \%$ confidence interval $(\mathrm{CI})=0.77-1.73, p=0.5]$ (Figure 2). The risk of first recurrence was higher in the 5ALA group although overlapping of the curves occurred in the later part of the follow-up. The median time to recurrence was 96.6 months in the WL group and 32.2 months in the 5ALA group.

Figures $3 \mathrm{~A}-3 \mathrm{C}$ demonstrate that there might be a smaller likelihood of later recurrence in the 5-ALA group compared to the WL group, even though the difference was not 
Table III. Number of the patients treated with bacillus Calmette-Guèrin (BCG) instillations after the TURBT and timing of the beginning of the instillation regimen.

\begin{tabular}{|c|c|c|c|c|c|c|c|c|c|c|c|c|c|}
\hline $\begin{array}{l}\text { Beginning of the } \\
\text { instillations (months) }\end{array}$ & 2 & 3 & 4 & 5 & 6 & 7 & 8 & 9 & 10 & 11 & 12 & 13 & All \\
\hline 5-ALA & 1 & 1 & & 1 & & 2 & 1 & & & & 1 & & 7 \\
\hline WL & & & 1 & & & & 2 & 1 & & 1 & & & 5 \\
\hline
\end{tabular}

WL: White light group; 5-ALA: 5-aminolevulinic acid group.

significant. This tendency was most obvious starting after 7.5 months of follow-up, that is, when 5-ALA had been used in the first two follow-up cystoscopies (Figure 3A).

During the first 13.5 months, five patients in the WL group and seven in the 5-ALA group were treated with bacillus Calmette-Guèrin instillations after TURBT. Table III shows the follow-up month in which the instillation regimen started. However, during the whole follow-up period, there were markedly more instillation regimens started in the WL group than in the 5-ALA group. In the WL group, 21 patients were treated with instillation therapy in contrast to only 13 in the 5-ALA group ( $p=0.2$, Pearson's Chi-square).

Of the 92 eligible patients in the 5-ALA group, 91 had data recorded for fluorescence. Of these 91 patients, 79 (87\%) showed positive fluorescence of the tumour(s) at the initial randomization cystoscopy.

A total of 52 events of biopsy-confirmed recurrence appeared in the 5-ALA group during the first 13.5 months. Out of the 52 events, $36(69 \%)$ had data recorded for fluorescence. Out of the 36 recurrences with fluorescence data, $32(89 \%)$ showed positive fluorescence.

Under the follow-up, two patients had progression in the WL group and four in the 5-ALA group, while one and two patients had advanced metastatic disease, respectively. No local or systemic adverse reactions following 5-ALA instillations were noticed.

\section{Discussion}

We did not find any statistically significant differences between the two treatment groups. However, we observed some non-significant differences. At the beginning of the follow-up period the risk of recurrence was lower in the WL group compared to the 5-ALA group. After two follow-up cystoscopies, at 7.5 months, the outcome was reversed, and a risk of recurrence seemed to be lower in the 5-ALA group.

Daneshmand et al. studied the use of PDD and flexible cystoscopes at the surveillance of 304 patients at a high risk of recurrence. Compared to WL only, they found $21 \%$ more malignant tumours with PDD, which resulted in a significantly reduced recurrence rate within 9 months $(p=0.026)(18)$. Our results report no benefit from using fluorescence cystoscopy, especially at the beginning of our follow-up time. After 7.5 months, one might detect a trend of decreasing risk of recurrence in the 5-ALA group. However, the use of 5-ALA type of agents in a repeated manner is hardly cost-effective using the agents currently available.

In the meta-analysis by Kausch et al. data was collected from prospective studies comparing WL with PDD from 1999 to 2008. Those authors' systematic review found that $20 \%$ more cases of papillary tumours and $39 \%$ more cases of CIS were detected by using PDD. Moreover, PDD guided cystoscopy resulted in fewer residual tumours $(\mathrm{OR}=0.28)$ and a higher recurrence-free survival $(p=0.00002)$ (19). These findings were also supported by a further metaanalysis by Mowatt et al. who identified a higher sensitivity for PDD over WL in the pooled estimates for analyses at both the patient (92\% vs 71\%) and the biopsy level (93\% vs. $65 \%$ ) (20). The specificity of PDD cystoscopy was lower than that with WL (63\% vs. 81\%) (20). Factors known to negatively affect the specificity of fluorescence cystoscopy are inflammation (21), previous intravesical chemotherapy (22), and recent transurethral resection of bladder tumours (TURBT) (23). Both 5-ALA and HAL appeared to be equally effective in PDD TURBT, which is the reason why studies with 5-ALA and HAL are grouped together in metaanalyses $(24,25)$.

Two prospective randomised studies that evaluated the impact of 5-ALA fluorescence cystoscopy guided TURBT on disease-recurrence rate provided controversial results (26, 27). The studies neither found higher tumour detection rates with PDD compared to WL nor any difference between groups with regard to recurrence-free and progression-free survival rates. However, intra-patient comparison of PDD in patients randomised to receive 5-ALA showed a higher tumour detection rate with fluorescent light than with WL in both studies $(26,27)$. A meta-analysis by Shen et al. found similar tumour detection rates for PDD cystoscopy $(91.8 \%)$ and WL cystoscopy (90.9\%) (28), but this analysis has been criticized for the use of multiple reports from the same series, as the findings are in contrast with those of other meta-analyses using similar data (29). 
The most likely explanation for our, at first sight conflicting, results is methodological in nature. In retrospect, our primary endpoint, the time to first recurrence, was not necessarily the adequate endpoint for estimating the possible benefits of the repeated use of PDD as compared with conventional WL. In theory, and as our data suggest, by using PDD repeatedly one may detect early recurrences more efficiently than using WL alone. As a result, the likelihood of non-recurrence in the PDD group inevitably becomes inferior to that in the WL group in early follow-up. Hence, it becomes impossible to show the superiority of PDD over WL using the Kaplan-Meier method when the time to recurrence is measured from the time point of the randomization cystoscopy. In fact, and although no significant differences were found with our limited number of patients, there was a trend indicating higher probability for fewer later recurrences in the PDD group compared to the WL group, especially after 7.5 months of follow-up. In accordance with this finding, markedly fewer instillation regimens were started in the 5-ALA group than in the WL group during the whole follow-up period.

Another factor that possibly contributes to our conflicting results was that our study protocol was executed by both experienced urologists and residents with limited experience in cystoscopy and PDD TURBT. PDD is a more technically demanding method than WL cystoscopy. Hence, insufficient training and experience of some individuals may have affected our results. Experienced urologists also obtain better results with both methods and play an important role for the quality of conventional and PDD TURBT (30). Moreover, our study included both patients with newly diagnosed NMIBC and those with recurrent tumours, and the two tumour entities are known to have very different risks of recurrence.

There were some additional technical problems. Although the optimum instillation time with 5-ALA to achieve the best visible difference has been found to be 2 to 4 hours, such an exposure time may not have been obtained in all our patients. The equipment was not identical in each hospital, and not infrequently, the obtained fluorescence was reported to be problematic. The drop-out rate was also exceptionally high, with the number of remaining eligible patients much lower than planned. Therefore, the likelihood of achieving statistically significant differences was lowered.

There are no standardized recommendations for the use of PDD for surveillance at regular intervals like we did in the present study during the first year. If PDD equipment is available, EAU guidelines recommends its use in TURBT in patients harboring a high grade tumour and/or positive cytology (31). The American Urological Association (AUA)Society of Urologic Oncology (SUO) guidelines for managing NMIBC state that "in a patient with NMIBC, a clinician should offer blue light cystoscopy at the time of
TURBT, if available, to increase detection and decrease recurrence" (32).

To date, the technology has improved and experience with PDD has accumulated. At present, urologists are more familiar and skilled with the PDD technique to obtain better results with TURBT. Regarding NMIBC, it is generally far easier to verify that a more appropriate treatment increases tumour detection and reduces recurrences than to show that it improves survival. Nevertheless, reducing disease recurrences by orderly TURBT may prevent worsening of the disease and affect disease control, quality of life, and overall costs. Our conclusion is that the study was insufficiently powered to demonstrate an advantage of the repeated use of ALA at the control cystoscopies during the first year of follow-up but a trend for lesser late recurrences in the ALA group was shown.

\section{Conflicts of Interest}

The Authors declare that they have no conflicts of interest.

\section{Authors' Contributions}

Kelloniemi E: Study design, Data collection, Drafting the manuscript, Revision. Järvinen R: Drafting the manuscript, Revision. Hellström P: Study design, Data collection, Drafting the manuscript, Revision. Rintala E: Study design, Revision. Aaltomaa S: Data collection, Revision. Isotalo T: Data collection. Innos K: Data collection. Kaasinen E: Analysis, Drafting the manuscript, Revision.

\section{Acknowledgements}

We are grateful to the following members of the FinnBladder Group for their contribution in providing us with long-term follow-up data on the patients of their center (urologist, center): Ilkka Perttilä, Helsinki; Kari Lehtoranta, Lahti; Ilkka Paananen, Oulu.

\section{References}

1 Burger M, Catto JW, Dalbagni G, Grossman HB, Herr H, Karakiewicz P, Kassouf W, Kiemeney LA, La Vecchia C, Shariat $\mathrm{S}$ and Lotan Y: Epidemiology and risk factors of urothelial bladder cancer. Eur Urol 63(2): 234-241, 2013. PMID: 22877502. DOI: 10.1016/j.eururo.2012.07.033

2 Brierley JD and Wittekind C (eds): TNM classification of malignant tumors. UICC International Union Against Cancer. $8^{\text {th }}$ edn, 2017, Wiley-Blackwell and UICC: New York, USA.

3 Kurth KH: Natural history and prognosis of untreated and treated superficial bladder cancer. In: Pagano F, Fair WR (eds). Superficial Bladder Cancer. Oxford: Isis medical media, pp. 4256, 1997.

4 Kaufman DS, Shipley WU and Feldman AS: Bladder cancer. Lancet 374(9685): 239-249, 2009. PMID: 19520422. DOI: 10.1016/S0140-6736(09)60491-8

5 Wijkström H, Cohen SM, Gardiner RA, Kakizoe T, Schoenberg $\mathrm{M}$, Steineck $\mathrm{G}$ and Tobisu K: Prevention and treatment of 
urothelial premalignant and malignant lesions. Scand J Urol Nephrol Suppl (205): 116-135, 2000. PMID: 11144892. DOI: $10.1080 / 00365590050509878$

6 Sylvester RJ, van der Meijden A, Witjes JA, Jakse G, Nonomura $\mathrm{N}$, Cheng C, Torres A, Watson R and Kurth KH: High-grade Ta urothelial carcinoma and carcinoma in situ of the bladder. Urology 66(6 Suppl 1): 90-107, 2005. PMID: 16399418. DOI: 10.1016/j.urology.2005.06.135

7 van Rhijn BW, Burger M, Lotan Y, Solsona E, Stief CG, Sylvester RJ, Witjes JA and Zlotta AR: Recurrence and progression of disease in non-muscle-invasive bladder cancer: From epidemiology to treatment strategy. Eur Urol 56(3): 430442, 2009. PMID: 19576682. DOI: 10.1016/j.eururo. 2009.06.028

8 Soloway MS, Murphy W, Rao MK and Cox C: Serial multiplesite biopsies in patients with bladder cancer. J Urol 120(1): $57-$ 59, 1978. PMID: 671606. DOI: 10.1016/s0022-5347(17)570378

9 Jakse G, Algaba F, Malmström PU and Oosterlinck W: A second-look TUR in T1 transitional cell carcinoma: why? Eur Urol 45(5): 539-546; discussion 546, 2004. PMID: 15082193. DOI: $10.1016 /$ j.eururo.2003.12.016

10 Kriegmair M, Baumgartner R, Knuechel R, Steinbach P, Ehsan A, Lumper W, Hofstädter F and Hofstetter A: Fluorescence photodetection of neoplastic urothelial lesions following intravesical instillation of 5-aminolevulinic acid. Urology 44(6): 836-841, 1994. PMID: 7985312. DOI: 10.1016/s00904295(94)80167-3

11 Hungerhuber E, Stepp H, Kriegmair M, Stief C, Hofstetter A, Hartmann A, Knuechel R, Karl A, Tritschler S and Zaak D: Seven years' experience with 5 -aminolevulinic acid in detection of transitional cell carcinoma of the bladder. Urology 69(2): 260264, 2007. PMID: 17320660. DOI: 10.1016/j.urology. 2006.10.015

12 Denzinger S, Burger M, Walter B, Knuechel R, Roessler W, Wieland WF and Filbeck T: Clinically relevant reduction in risk of recurrence of superficial bladder cancer using 5aminolevulinic acid-induced fluorescence diagnosis: 8-year results of prospective randomized study. Urology 69(4): 675679, 2007. PMID: 17445650. DOI: 10.1016/j.urology. 2006.12.023

13 Filbeck T, Pichlmeier U, Knuechel R, Wieland WF and Roessler W: Clinically relevant improvement of recurrence-free survival with 5-aminolevulinic acid induced fluorescence diagnosis in patients with superficial bladder tumors. J Urol 168(1): 67-71, 2002. PMID: 12050494.

14 Fradet Y, Grossman HB, Gomella L, Lerner S, Cookson M, Albala D, Droller MJ and PC B302/01 Study Group: A comparison of hexaminolevulinate fluorescence cystoscopy and white light cystoscopy for the detection of carcinoma in situ in patients with bladder cancer: A phase III, multicenter study. J Urol 178(1): 68-73; discussion 73, 2007. PMID: 17499291. DOI: $10.1016 /$ j.juro.2007.03.028

15 Grossman HB, Gomella L, Fradet Y, Morales A, Presti J, Ritenour C, Nseyo U, Droller MJ and PC B302/01 Study Group: A phase III, multicenter comparison of hexaminolevulinate fluorescence cystoscopy and white light cystoscopy for the detection of superficial papillary lesions in patients with bladder cancer. J Urol 178(1): 62-67, 2007. PMID: 17499283. DOI: 10.1016/j.juro.2007.03.034
16 Jichlinski P, Guillou L, Karlsen SJ, Malmström PU, Jocham D, Brennhovd B, Johansson E, Gärtner T, Lange N, van den Bergh $\mathrm{H}$ and Leisinger HJ: Hexyl aminolevulinate fluorescence cystoscopy: New diagnostic tool for photodiagnosis of superficial bladder cancer-A multicenter study. J Urol 170(1): 226-229, 2003. PMID: 12796694. DOI: 10.1097/01.ju. 0000060782.52358 .04

17 Sauter G and Amin M (eds): Tumours of the urinary system: Non-invasive urothelial neoplasias. In: WHO classification of classification of tumours of the urinary system and male genital organs. A.F. 2004, IARCC Press: Lyon.

18 Daneshmand S, Patel S, Lotan Y, Pohar K, Trabulsi E, Woods M, Downs T, Huang W, Jones J, O'Donnell M, Bivalacqua T, DeCastro J, Steinberg G, Kamat A, Resnick M, Konety B, Schoenberg M, Jones JS and Flexible Blue Light Study Group Collaborators: Efficacy and safety of blue light flexible cystoscopy with hexaminolevulinate in the surveillance of bladder cancer: A phase III, comparative, multicenter study. J Urol 199(5): 1158-1165, 2018. PMID: 29203268. DOI: 10.1016/ j.juro.2017.11.096

19 Kausch I, Sommerauer M, Montorsi F, Stenzl A, Jacqmin D, Jichlinski P, Jocham D, Ziegler A and Vonthein R: Photodynamic diagnosis in non-muscle-invasive bladder cancer: A systematic review and cumulative analysis of prospective studies. Eur Urol 57(4): 595-606, 2010. PMID: 20004052. DOI: 10.1016/ j.eururo.2009.11.041

20 Mowatt G, N'Dow J, Vale L, Nabi G, Boachie C, Cook JA, Fraser C, Griffiths TR and Aberdeen technology assessment review (TAR) group: Photodynamic diagnosis of bladder cancer compared with white light cystoscopy: Systematic review and meta-analysis. Int J Technol Assess Health Care 27(1): 3-10, 2011. PMID: 21262078. DOI: 10.1017/S0266462310001364

21 Kriegmair M, Baumgartner R, Knüchel R, Stepp H, Hofstädter $\mathrm{F}$ and Hofstetter A: Detection of early bladder cancer by 5aminolevulinic acid induced porphyrin fluorescence. J Urol 155(1): 105-9; discussion 109-10, 1996. PMID: 7490803.

22 Grimbergen MC, van Swol CF, Jonges TG, Boon TA and van Moorselaar RJ: Reduced specificity of 5-ALA induced fluorescence in photodynamic diagnosis of transitional cell carcinoma after previous intravesical therapy. Eur Urol 44(1): 51-56, 2003. PMID: 12814675. DOI: 10.1016/s03022838(03)00210-0

23 Filbeck T, Roessler W, Knuechel R, Straub M, Kiel HJ and Wieland WF: 5-aminolevulinic acid-induced fluorescence endoscopy applied at secondary transurethral resection after conventional resection of primary superficial bladder tumors. Urology 53(1): 77-81, 1999. PMID: 9886592. DOI: 10.1016/ s0090-4295(98)00430-0

24 Burger M, Stief CG, Zaak D, Stenzl A, Wieland WF, Jocham D, Otto $\mathrm{W}$ and Denzinger S: Hexaminolevulinate is equal to 5aminolevulinic acid concerning residual tumor and recurrence rate following photodynamic diagnostic assisted transurethral resection of bladder tumors. Urology 74(6): 1282-1286, 2009. PMID: 19819538. DOI: 10.1016/j.urology.2009.06.088

25 Oude Elferink P and Witjes JA: Blue-light cystoscopy in the evaluation of non-muscle-invasive bladder cancer. Ther Adv Urol 6(1): 25-33, 2014. PMID: 24489606. DOI: 10.1177/ 1756287213510590

26 Schumacher MC, Holmäng S, Davidsson T, Friedrich B, Pedersen $\mathrm{J}$ and Wiklund NP: Transurethral resection of non- 
muscle-invasive bladder transitional cell cancers with or without 5-aminolevulinic acid under visible and fluorescent light: Results of a prospective, randomised, multicentre study. Eur Urol 57(2): 293-299, 2010. PMID: 19913351. DOI: 10.1016/j.eururo. 2009.10.030

27 Stenzl A, Penkoff H, Dajc-Sommerer E, Zumbraegel A, Hoeltl L, Scholz M, Riedl C, Bugelnig J, Hobisch A, Burger M, Mikuz $\mathrm{G}$ and Pichlmeier U: Detection and clinical outcome of urinary bladder cancer with 5-aminolevulinic acid-induced fluorescence cystoscopy : A multicenter randomized, double-blind, placebocontrolled trial. Cancer 117(5): 938-947, 2011. PMID: 21351082. DOI: $10.1002 / \mathrm{cncr} .25523$

28 Shen P, Yang J, Wei W, Li Y, Li D, Zeng H and Wang J: Effects of fluorescent light-guided transurethral resection on nonmuscle-invasive bladder cancer: A systematic review and metaanalysis. BJU Int 110(6 Pt B): E209-E215, 2012. PMID: 22288379. DOI: 10.1111/j.1464-410X.2011.10892.x

29 Rink M, Babjuk M, Catto JW, Jichlinski P, Shariat SF, Stenzl A, Stepp H, Zaak D and Witjes JA: Hexyl aminolevulinate-guided fluorescence cystoscopy in the diagnosis and follow-up of patients with non-muscle-invasive bladder cancer: A critical review of the current literature. Eur Urol 64(4): 624-638, 2013. PMID: 23906669. DOI: 10.1016/j.eururo.2013.07.007
30 Jancke G, Rosell J and Jahnson S: Impact of surgical experience on recurrence and progression after transurethral resection of bladder tumour in non-muscle-invasive bladder cancer. Scand J Urol 48(3): 276-283, 2014. PMID: 24286506. DOI: 10.3109/ 21681805.2013.864327

31 Babjuk M, Böhle A, Burger M, Capoun O, Cohen D, Compérat EM, Hernández V, Kaasinen E, Palou J, Rouprêt M, van Rhijn BWG, Shariat SF, Soukup V, Sylvester RJ and Zigeuner R: EAU guidelines on non-muscle-invasive urothelial carcinoma of the bladder: Update 2016. Eur Urol 71(3): 447-461, 2017. PMID: 27324428. DOI: 10.1016/j.eururo.2016.05.041

32 Chang SS, Boorjian SA, Chou R, Clark PE, Daneshmand S, Konety BR, Pruthi R, Quale DZ, Ritch CR, Seigne JD, Skinner EC, Smith ND and McKiernan JM: Diagnosis and treatment of non-muscle invasive bladder cancer: AUA/SUO guideline. J Urol 196(4): 1021-1029, 2016. PMID: 27317986. DOI: 10.1016/j.juro.2016.06.049

Received December 21, 2020

Revised February 26, 2021

Accepted March 10, 2021 